\title{
Recycling as appropriate behavior: a review of survey data from selected recycling education programs in Michigan
}

\author{
Raymond De Young \\ The University of Michigan, School of Natural Resources, Ann Arbor, MI 48109-1115 (U.S.A.)
}

(Received July 13, 1989; accepted in revised form September 30, 1989)

\begin{abstract}
De Young, R., 1990. Recycling as appropriate behaviour: a review of survey data from selected recycling education programs in Michigan. Resour. Conserv. Recycl., 3: 253-266.

Data from surveys conducted by six separate recycling education programs funded under the Clean Michigan Fund are compared. The findings indicate that a strong pro-recycling attitude exists among the populations sampled with a significant percentage of respondents planning to increase their level of recycling in the future. To aid this increase in participation these data suggest that education efforts should focus on helping people become more familiar with the details of how to recycle. And finally, these data support the idea that efforts to promote waste reduction and recycling behavior should focus on non-monetary motives.
\end{abstract}

\section{INTRODUCTION}

Recycling of household solid waste offers one means of managing the burden of municipal solid waste. Yet if recycling is to make a major impact it is vital that people make this behavior the norm rather than the exception. Recycling education programs are a major means of achieving such a state. They seek to increase society's knowledge about waste reduction and recycling behaviors, develop a positive attitude about such behavior, and encourage nonparticipating households to begin and participating households to increase their behavior. The research reported here utilized survey data to assess the degree to which several recycling education programs in Michigan are meeting these goals.

\section{METHODS}

As a part of their Clean Michigan Fund program, the Michigan Department of Natural Resources (MDNR) funded thirteen recycling education pro- 
grams for the period from early 1986 through the middle of 1987 . A number of programs utilized surveys of randomly selected citizens to assess the effectiveness of their education efforts. The author was contracted by the MDNR to provide these programs with help in conducting written/mail-back or telephone surveys on recycling attitudes and behavior. The surveys were conducted by the individual programs using their paid or volunteer staff.

\section{The samples}

The survey data presented below are from six separate recycling education programs. A comparison across programs is possible because each included, as part of their survey instrument, the set of six standardized questions described below. The first four programs listed had their data analyzed by the author. The last two programs provided summaries of their data analysis. The six participating programs, their sample size and whether they employed a telephone survey or a mail-back written questionnaire, are identified in Table 1.

All samples were drawn randomly from the local communities except for the Northern Michigan Recycling Cooperative (NMRC) program. The NMRC conducted one survey of local government officials and another of people who, at one time or another, had called the recycling information telephone number to ask a question about recycling. Neither of these samples can be considered completely random.

The Portage program was the only community to conduct a two-phase evaluation. A base-line survey was completed just prior to the start of their education effort and a follow-up survey was administered near the end of the

TABLE 1

Description of surveys

\begin{tabular}{llcc}
\hline Program location & $\begin{array}{l}\text { Survey } \\
\text { type }\end{array}$ & $\begin{array}{l}\text { Sample } \\
\text { size }\end{array}$ & $\begin{array}{c}\text { Community } \\
\text { population }\end{array}$ \\
\hline Barry County & Telephone & 95 & 46300 \\
Huntington Woods & Mail & 286 & 6700 \\
Jackson County & Telephone & 86 & 151000 \\
Monroe County & Mail & 36 & 142000 \\
Northern Michigan Recycling Coop & Mail & $20 / 37^{\mathrm{a}}$ & 410000 \\
Portage & Telephone & $259 / 323^{\mathrm{b}}$ & 40200 \\
Publishers Paper Company Study & & & \\
$\quad$ Metropolitan areas & Telephone & 1500 & \\
Rural Oregon & Telephone & 250 & \\
\hline
\end{tabular}

${ }^{a}$ Local officials and 1-800 number respondents, respectively.

'Sample size for the pre-test and post-test, respectively. 
effort [1]. The other five programs conducted one survey near the end of their education effort.

Data from all six programs are also contrasted with data from a similar survey conducted in 1984 by the Intercept Research Corporation for Publishers Paper Company of Lake Oswego, Oregon. This study was conducted to learn more about west coast recycling attitudes and behaviors [2]. The communities surveyed included Portland, Seattle, San Francisco, Denver, Salt Lake City, Vancouver, B.C. and eastern rural Oregon. This telephone survey included a set of six questions virtually identical to the six standardized questions used in the Michigan studies. The randomly drawn sample size was 1750 with 1500 from metropolitan areas ( 250 from each city) and 250 from rural areas of Oregon.

\section{The survey questions}

The survey questions were designed to assess people's attitude about recycling, self-reported behavior, future behavioral intentions, perceived barriers to recycling and motives for recycling. The specific questions are described below.

In an effort to assess their general attitude toward recycling the respondents were asked to evaluate the importance of recycling. For five of the recycling education program surveys and the Publishers Paper Company survey the full text of the question read, "How important is recycling to the preservation of the environment and the conservation of our natural resources?" For the Northern Michigan Recycling Cooperative (NMRC) survey of local government officials the question was worded, "Please indicate how important you feel recycling is as a component of solid waste management?" The questionnaires used a five-point Likert response scale ranging from "not important" to "very important". A "don't know" response was also included. The users of the NMRC telephone number were not asked an attitudinal question.

Most of the surveys asked the respondents to self-report their recycling behavior. Based on their answer the respondents were classified as a recycler or a non-recycler. This questions was not asked of the Huntington Woods and Monroe County respondents. For the other Michigan communities, this item was worded, "Are you a recycler?" In the Publishers Paper Company survey this question was worded, "Does your household currently recycle newspaper, cardboard, glass or aluminium?"

It is not unusual for respondents to report their behavior intent rather than their actual behavior. For this reason it is often preferable to classify a respondent as a recycler using direct observational data. There are, however, other means of improving the internal validity of a study. For instance, one gains a check on self-reported recycling behavior by asking what materials people recycle. The respondents were asked to consider a list of materials and 
indicate which ones they recycled. All the Michigan programs included six standard recycling materials in their list: newspaper, cardboard, used oil, plastic, glass and other. Several programs also included such materials as magazines, cans, or aluminum.

In an effort to assess the direction of change in future recycling behavior, respondents in five of the Michigan programs and the Publishers Paper Company study were asked, "In the future, do you plan to increase your recycling efforts, decrease your recycling efforts, or maintain your current recycling efforts?" Note that for the Portage program only those respondents who had indicated that they currently recycled were asked this question. The Northern Michigan Recycling Cooperative respondents were not asked this question.

In any attempt to change people's behavior one must address the problem of barriers people identify as preventing them from recycling. The respondents were asked the stem question, "What are some reasons you don't recycle more?' and were given a list of several reasons they could check off. The reasons are listed in Table 2.

Finally, an item was included in all six Michigan surveys that assessed what some of the motives for recycling might be. The respondents were presented with one general stem question worded as follows, "Below are several reasons why people might recycle materials. Please indicate on a five-point scale the degree to which they apply to you." The scale had the lower tag of "not at all" and the upper tag of "very great deal". A "don't know" response was also included. The stem question was purposely worded to get at possible rather

\section{TABLE 2}

Survey question on perceived barriers to recycling ${ }^{a}$

Questions

Recycling is too much of a hassle

There is not enough room to store the items

There is not enough time to sort or bundle all the items

I simply forget to recycle

I don't know just what to do

Recycling cost me too much money ${ }^{b}$

The messiness recycling causes around the house

There is no facility/pick-up service available

${ }^{a}$ Depending on the program, the stem question was asked of (1) all respondents, or (2) the recycling and non-recycling subsamples of respondents. When the sample included all respondents or recyclers, the item was worded "What are some reasons you don't recycle more?" Where the sample included non-recyclers the question was worded, "What are some reasons you don't recycle?" For the Northern Michigan Recyclers Cooperative (NMRC) survey, this questions was asked of the local government officials.

${ }^{b}$ For the Publishers Paper Company survey the item concerning costs was worded, "Not worth the money". 
than current motives since in no instance was there any direct monetary reward offered for recycling nor any strong tie to a charity. This stem question was followed by the following specific items which the respondents were asked to rate: (1) "I recycle to help conserve natural resources," (2) "I recycle to help support charity," (3) "I recycle to earn money," and (4) "I recycle because it seems like the right thing to do." The Northern Michigan Recycling Coop study asked the local officials whether they felt the public would be motivated to recycle for these four reasons.

\section{RESULTS AND DISCUSSION}

The results are presented in Tables 3 through 8 and reviewed below, question by question.

\section{Recycling attitude}

For all program surveys, about $85 \%$ of the respondents indicated they thought recycling was extremely important to the preservation of the environment (i.e., selected categories 4 or 5 on the five-point scale). As shown in Table 3 the mean score on this question ranged from 4.22 to 4.62 (out of a maximum possible score of 5 ) with the Michigan communities having slightly higher mean values than the Publishers Paper Company sample.

The data for Portage, the only program to conduct a base-line and followup survey, show a drop over time. About $86 \%$ of the Portage respondents indicated recycling was extremely important in the base-line survey while about $81 \%$ indicated recycling was extremely important in the follow-up sur-

\section{TABLE 3}

Mean ratings on the recycling attitude question

\begin{tabular}{lll}
\hline Program location & Mean & $\begin{array}{l}\text { Standard } \\
\text { deviation }\end{array}$ \\
\hline Barry County & 4.62 & 0.67 \\
Huntington Woods & 4.42 & 0.88 \\
Jackson County & 4.40 & 0.86 \\
Monroe County $_{\text {NMRC (local officials) }}{ }^{\mathrm{a}}$ & 4.55 & 0.69 \\
Portage (base-line respondents) $_{\text {Portage (follow-up respondents) }}$ & 4.59 & 0.79 \\
Publishers Paper (entire sample) & 4.40 & 0.88 \\
$\quad$ Metropolitan areas & 4.21 & 1.01 \\
$\quad$ Rural Oregon & 4.27 & 0.94 \\
\hline
\end{tabular}

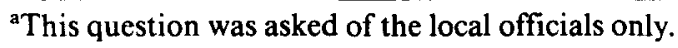


vey. This difference, although in the direction of the base-line survey, is slight. In part, the apparent failure of the Portage program to improve the respondent's attitude toward recycling might be partially explained by the extremely positive attitude held by the respondents. With a vast majority of the respondents holding a strong positive attitude in the base-line survey there was limited room for improvement.

Taken together these data are encouraging. In all instances a vast majority of respondents viewed recycling as an important behavior. The opportunity for recycling education programs to improve upon the current pro-recycling attitude may be limited. With little room for improvement, programs might be well advised to concentrate on something other than people's attitude about the behavior.

\section{Recycling behavior}

The percentage of respondents indicating they currently recycled was high, ranging from 54 to $86 \%$. In all instances the Michigan data are similar to the Publishers Paper Company study findings (see Table 4). The Portage program data showed a very modest $1 \%$ increase in recycling behavior between the base-line and the follow-up survey.

It is worth noting that a surprisingly high percentage of respondents reported that they were recyclers. Although past studies [3] of recycling behavior have reported similar percentages these data should be viewed with at least some caution. There are a number of reasons to believe that the figures are slightly inflated. Foremost is the fact that recycling is becoming a form of socially acceptable behavior. Recycling, once an eccentric activity, may now be the social norm. One may credit this change to environmental education

TABLE 4

Responses on the recycling behavior question ${ }^{\mathrm{a}}$

\begin{tabular}{lll}
\hline Program location & $\begin{array}{l}\text { Recyclers } \\
(\%)\end{array}$ & $\begin{array}{l}\text { Non-recyclers } \\
(\%)\end{array}$ \\
\hline Barry County & 73.7 & 26.3 \\
Jackson County & 63.1 & 36.9 \\
NMRC (1-800 number respondents) ${ }^{\mathrm{b}}$ & 86.5 & 13.5 \\
Portage (base-line respondents) $_{\text {Portage (follow-up respondents) }}^{54.4}$ & 45.6 \\
Publishers Paper (entire sample) & 55.5 & 44.5 \\
$\quad$ Metropolitan areas & 68.0 & 32.0 \\
Rural Oregon & 69.0 & 31.0 \\
\hline
\end{tabular}

${ }^{a}$ This question was not asked of the Huntington Woods or Monroe County respondents.

${ }^{\mathrm{b}}$ This question was asked of the 1-800 number respondents only. 
successes over the last decade. However, with such success can come an "overreporting" of the behavior. Furthermore, respondents may sometimes indicate their intentions to recycle rather than their actual behavior. Without utilizing an extensive definition of what the survey means by "recycling" or holding the respondent to a tight time frame for their assessment (both somewhat counterproductive to a brief, readable questionnaire ), respondents may recall a wide range of behaviors occurring over a multi-year period and assess all of them to be instances of recycling. For instance, respondents may consider returning deposit bottles to the market twice during the last year as recycling behavior.

However, even if caution is warranted, these data still indicate that citizens in Michigan, as represented by the respondents, had come to accept recycling as an important and appropriate behavior. In Michigan, a pro-recycling attitude had been translated into a stated willingness to recycle.

\section{Materials recycled}

Reported recycling behavior has always varied by material. For instance, in an earlier survey approximately $55 \%$ of the residents of Seattle, Washington indicated that they recycled newspaper, $42 \%$ recycled glass containers and $38 \%$ recycled aluminium cans. Approximately $20 \%$ indicated that they recycled all three materials [4]. Recycling practitioners have suggested a tentative sequence with newspapers being recycled most often followed by glass containers and metal cans, and then other materials.

The data from both the Clean Michigan Fund programs and the Publishers Paper Company study follows the general sequence outlined above (see Table 5 ). Newsprint is recycled by the largest percentage of respondents (ranging from 31 to $92 \%$ ). The next most widely recycled material varies depending upon the community studied with glass containers, metal cans or aluminum having similar percentages (ranging from 7 to $46 \%$ of the respondents).

It is worth noting that two materials which were relatively new to the Michigan recycled waste stream, used oil and plastics, were being recycled by a significant percentage of respondents. Used oil was being recycled by approximately $20 \%$ of the respondents (with a range of 8 to $51 \%$ ) and plastics by about $10 \%$ of the respondents (with a range of 4 to $19 \%$ ).

In the case of Huntington Woods where both used motor oil and plastic milk jugs were promoted in their education program, there was a significant number of respondent $s$ (approximately $18 \%$ ) indicating that they recycled these products. The Northern Michigan Recyclers Cooperative survey of users of their 1-800 recycling information telephone number indicated a slight majority ( $51 \%$ of the respondents) recycled used motor oil. This percentage is all the more impressive when one realizes that the recycling of used motor oil was not a major focus of the NMRC education effort. 
TABLE 5

Responses on the materials recycled question ${ }^{2}$

\begin{tabular}{|c|c|c|c|c|c|c|c|c|c|}
\hline \multirow[t]{2}{*}{ Program location } & \multicolumn{9}{|c|}{ Percentage responding yes for each material } \\
\hline & NEWS & MAGS & CARD & OIL & PLAS & GLAS & CANS & ALUM & OTHR \\
\hline Barry County & 50.5 & 28.4 & 13.7 & 22.1 & 4.2 & 24.3 & 18.9 & 20.0 & 15.8 \\
\hline Huntington Woods ${ }^{b}$ & 67.1 & - & 5.2 & 17.5 & 18.9 & 4.9 & - & - & 7.0 \\
\hline Jackson County & 30.6 & 15.3 & 8.2 & 18.8 & 7.1 & 43.5 & 30.6 & 31.8 & 4.7 \\
\hline Monroe County & 45.7 & 22.9 & 2.9 & 8.3 & 13.9 & 22.2 & 25.0 & 22.2 & 2.8 \\
\hline NMRC ( $1-800$ respondents $)^{c}$ & 59.4 & - & 43.2 & 51.4 & 10.8 & 24.3 & 29.7 & 18.9 & 16.2 \\
\hline Portage (base-line survey) & 51.0 & 40.9 & 22.0 & 19.7 & 2.3 & 6.9 & 8.1 & 10.0 & 4.6 \\
\hline Portage (follow-up survey) & 47.4 & 36.8 & 16.1 & 25.1 & 10.5 & 13.6 & 15.2 & 12.4 & 3.7 \\
\hline Publishers Paper & 86.0 & 16.0 & 21.0 & - & - & 27.0 & - & 44.0 & 4.0 \\
\hline Metropolitan areas & 85.0 & 16.0 & 20.0 & - & - & 26.0 & - & 46.0 & 2.0 \\
\hline Rural Oregon & 92.0 & 18.0 & 27.0 & - & - & 31.0 & - & 27.0 & 1.0 \\
\hline aNEWS =newsprint & & GLAS & & h & $z$ & 10 & & & \\
\hline MAGS $=$ magazines & & CANS & $=$ metal & cans & & & & & \\
\hline CARD = corrugated cardboard & & ALUM & $=$ alumin & num ( & foil, & ls) & & & \\
\hline$=$ used motor oil & & OTHR & $=$ other $\mathrm{n}$ & materi & ials (un & specified & & & \\
\hline PLAS = plastic (no type specif & ed) & - & $=$ item $n$ & lot incl & luded o & $\mathrm{n}$ the sur & rvey $\mathrm{i}$ & rument & \\
\hline
\end{tabular}

'The Huntington Woods questionnaire asked separately about "returnable bottles" and "non-returnable glass'. The percentage shown is for the recycling of non-returnable glass containers.

'This question was asked of the $1-800$ number respondents only.

Finally, the Portage program was apparently most effective in promoting the recycling of such materials as used motor oil, plastic, glass, and cans. It is worth noting that prior to the Portage Recycling Program there were few places in or around Portage where people could readily recycle used motor oil, plastic, glass or cans. Since the establishment of the Portage Program these materials can easily be recycled at the Portage Recycling Center, a point made clear in their education efforts. These data suggest that the Portage Program was effective at promoting the recycling of non-paper related materials, including the newer entries to the recycling waste stream (i.e., used oil and plastic).

\section{Behavioral intent}

A majority of the respondents (ranging from 57 to $78 \%$ ) intended to maintain their current level of recycling behavior (refer to Table 6). Virtually all of the remaining respondents (ranging from 20 to $42 \%$ ) indicated that they planned to increase their level of recycling activity in the future. These data compare very favorably with the Publishers Paper survey data where only $21 \%$ indicated they planned to increase their recycling behavior.

The Portage data document a dramatic shift in future recycling plans among the survey respondents. Approximately $12 \%$ of the respondents switched from 
TABLE 6

Respondent's future intentions with respect to recycling ${ }^{a}$

\begin{tabular}{|c|c|c|c|}
\hline Program location & $\begin{array}{l}\text { Increase } \\
\text { behavior } \\
(\%)\end{array}$ & $\begin{array}{l}\text { Maintain } \\
\text { behavior } \\
(\%)\end{array}$ & $\begin{array}{l}\text { Decrease } \\
\text { behavior } \\
(\%)\end{array}$ \\
\hline Barry County & 37.0 & 63.0 & 0 \\
\hline Huntington Woods & 37.5 & 62.5 & 0 \\
\hline Jackson County & 28.6 & 71.4 & 0 \\
\hline Monroe County & 42.4 & 57.6 & 0 \\
\hline Portage (base-line respondents) ${ }^{b}$ & 20.2 & 78.4 & 1.4 \\
\hline Portage (follow-up respondents) ${ }^{\mathrm{b}}$ & 32.4 & 66.5 & 1.1 \\
\hline Publishers Paper (entire sample) ${ }^{c}$ & 21.0 & 74.0 & 1.0 \\
\hline Metropolitan areas & 21.0 & 74.0 & 2.0 \\
\hline Rural Oregon & 21.0 & 73.0 & 0 \\
\hline
\end{tabular}

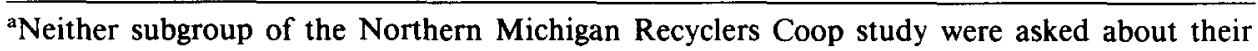
intentions.

bPercentages for Portage are based upon the subsample of respondents who indicated they currently recycled ( $N=139$ and 173 , respectively).

'The percentage shown for the Publishers paper Company survey do not add to $100 \%$ due to those respondents who did not know their future intentions.

planning to just maintain their current level of recycling behavior to planning to increase their level of activity.

Overall, a significant percentage of respondents indicated they had plans to increase their level of recycling behavior in the future. Furthermore, virtually none of the respondents indicated that they planned to recycle less in the future. These data bode well for future recycling efforts since they suggest that participation rates can be expected to climb. However, one must capitalize on these good intentions. Future programs should focus their efforts on motivating people to turn their good intentions into actual behavior. This might be accomplished by helping people to overcome perceived barriers, by promoting the recycling of a wider range of materials and by employing motivational techniques.

\section{Barriers to recycling}

The major perceived barriers to recycling are surprisingly consistent regardless of which subgroup, recyclers or non-recyclers, is examined (see Table 7). The respondents reported the following problems, in approximate order: (1) not enough information, (2) not enough room to store the items being recycled, and (3) recycling being too much of a hassle. The messiness recycling can cause and recycling facilities not being available were also mentioned as reasons people do not recycle more or at all. 
TABLE 7

Responses on the barriers to recycling question ${ }^{\mathrm{a}}$

\begin{tabular}{|c|c|c|c|c|c|c|c|c|c|}
\hline \multirow[t]{2}{*}{ Program location } & \multicolumn{9}{|c|}{ Percentage responding yes for each barrier } \\
\hline & HASS & ROOM & TIME & FORG & INFO & COST & MESS & CONV & OTHR \\
\hline \multicolumn{10}{|l|}{ Using entire sample } \\
\hline Barry County & 27.4 & 45.3 & 24.2 & 24.2 & 56.8 & 10.5 & 40.0 & - & - \\
\hline Huntington Woods & 21.3 & 32.5 & 17.5 & 34.6 & 17.5 & 1.7 & 25.2 & 23.8 & - \\
\hline Jackson County & 34.1 & 47.1 & 23.5 & 30.6 & 37.6 & 10.6 & 30.6 & 43.5 & - \\
\hline Monroe County & 47.1 & 51.4 & 36.4 & 33.3 & 51.6 & 12.5 & 50.0 & - & - \\
\hline NMRC (local officials) ${ }^{b}$ & 50.0 & 40.0 & 30.0 & 30.0 & 55.0 & 25.0 & 30.0 & 50.0 & 10.0 \\
\hline \multicolumn{10}{|l|}{ Using subsample of recyclers } \\
\hline Portage (base-line) $N=141$ & 30.4 & 31.9 & 22.7 & 17.0 & 45.4 & 5.0 & 18.4 & - & 11.3 \\
\hline Portage (follow-up) $N=177$ & 50.6 & 38.7 & 30.5 & 37.7 & 29.5 & 6.9 & 31.0 & - & 9.8 \\
\hline Publishers Paper $N=898$ & 24.0 & 8.0 & 10.0 & 5.0 & - & 4.0 & - & 11.0 & 20 \\
\hline Metro areas $N=786$ & 24.0 & 7.0 & 10.0 & 4.0 & - & 4.0 & - & 9.0 & 2.0 \\
\hline Rural Oregon $N=112$ & 19.0 & 15.0 & 9.0 & 7.0 & - & 5.0 & - & 26.0 & 0 \\
\hline \multicolumn{10}{|c|}{ Using subsample of non-recyclers } \\
\hline Portage (base-line ) $N=118$ & 44.1 & 46.6 & 27.1 & 153 & 32.2 & 11.0 & 22.0 & - & 20.3 \\
\hline Portage (follow-up) $N=145$ & 51.0 & 42.1 & 38.6 & 34.5 & 47.6 & 9.7 & 33.0 & - & 9.1 \\
\hline Publishers Paper $N=560$ & 37.0 & 8.0 & 11.0 & 4.0 & - & 4.0 & - & 26.0 & 4.0 \\
\hline Metro areas $N=463$ & 40.0 & 8.0 & 11.0 & 5.0 & - & 4.0 & - & 23.0 & 4.0 \\
\hline Rural Oregon $N=97$ & 25.0 & 7.0 & 7.0 & 3.0 & - & 6.0 & - & 43.0 & 5.0 \\
\hline
\end{tabular}

$\begin{aligned} &{ }^{a} \mathrm{HASS}=\text { recycling is too much of a hassle } \\ & \text { ROOM }=\text { there is no room to store sorted items } \\ & \text { TIME }=\text { there is no time to sort or bundle all the } \\ & \text { items } \\ & \text { FORG }=\text { I simply forget to recycle } \\ & \text { INFO }=\text { I don't know just what to do }\end{aligned}$

'This question was asked of the local officials only.

$$
\begin{aligned}
\text { COST }= & \text { recycling costs me too much money } \\
\text { MESS }= & \text { the messiness recycling causes around the } \\
& \text { house }
\end{aligned}
$$

It is interesting to note that the local government officials surveyed by the Northern Michigan Recycling Coop differed most dramatically from the other respondents (i.e., the public) on at least one of the nine reasons. These officials were asked, "Please check those items that you believe people find to be barriers to recycling." The data indicate that the local government officials overstated the salience of personal cost as a barrier to increased recycling.

The Publishers Paper Company study found that the major barrier among recyclers and non-recyclers alike was the perception that recycling was too much of a hassle. While something being "too much of a hassle" seems like a vague concept, respondents had shown no problem in identifying it as a major reason they do not recycle more or at all. Previous research supports the notion of inadequate storage space being a major barrier to increased recycling activity [3].

A particularly interesting finding is that a lack of information (i.e., not 
knowing exactly what to do to recycle) consistently shows up as a major reason people do not recycle more often or at all. One should not interpret this as an attitudinal issue. People are not saying that they consider recycling to be an inappropriate behavior. They are, instead, indicating a lack of familiarity with the basic aspects of the behavior - they do not know what they need to do to recycle glass jars sitting in their sink. The Portage data show a dramatic contrast between the recycling and non-recycling subsamples on the information issue. Recyclers may have been influenced by the formation made available during the education effort - they reported information as much less of a barrier to increased behavior in the follow-up survey. For non-recyclers just the opposite effect was found. In a rank order analysis of the Portage data it was found that, for recyclers, the major issue at the time of the baseline survey was the information item. This same item underwent the largest change in ranking dropping to number six by the follow-up survey. For the non-recycler subsample, the information item underwent only a minor ranking change. This item was ranked third in the base-line survey and actually rose to second by the follow-up survey [1].

Why people do not recycle more (or at all) gets at the major issue confronting every recycling education effort. Overall these data suggest that education efforts should concentrate on helping people become familiar with the desired behavior. This finding is supported by a recent study which found that nonrecyclers differed significantly from recyclers mainly in the degree to which they required additional information about the behavior [5].

\section{Recycling motivation}

The data reported in Table 8 indicates the same motivational tendency exists among the respondents of both the Clean Michigan Fund Programs and the Publishers paper Company survey. The respondents are most inclined toward the non-monetary motive of recycling to help conserve natural resources. Closely behind this motive is recycling to help support a charity and recycling because it seems like the right thing to do. Ranked a distant fourth is the economic motive of recycling to earn money. Clearly, a majority of the respondents do not consider recycling to earn money to be a strong motive for the behavior.

These findings are supported by current research on conservation behavior. Clearly, research has confirmed that at least a modest tie exists between extrinsic (particularly economic) motivation and conservation behavior [6]. However, research has also documented an association between intrinsic motivation and recycling behavior [7].

And finally, it was again found that the decision-makers held a unique view of the public they represent. The study by the Northern Michigan Recycling Coop shows that local officials evaluated the public's motives somewhat dif- 
TABLE 8

Mean ratings on the recycling motivation questions ${ }^{a}$

\begin{tabular}{|c|c|c|}
\hline Program location & Mean & Standard deviation \\
\hline \multicolumn{3}{|l|}{ Recycle to help conserve natural resources } \\
\hline Barry County & 4.35 & 0.96 \\
\hline Huntington Woods & 4.15 & 1.08 \\
\hline Jackson County & 4.14 & 1.00 \\
\hline NMRC (1-800 number respondents) & 4.41 & 1.01 \\
\hline NMRC (local officials) & 4.10 & 1.15 \\
\hline Portage (base-line respondents) & 3.88 & 1.39 \\
\hline Portage (follow-up respondents) & 3.97 & 1.32 \\
\hline Publishers Paper (entire sample) & 4.10 & 1.27 \\
\hline Metropolitan areas & 4.07 & 1.27 \\
\hline Rural Oregon & 4.30 & 1.24 \\
\hline \multicolumn{3}{|l|}{ Recycle to help support a charity } \\
\hline Barry County & 4.31 & 1.19 \\
\hline Huntington Woods & 3.90 & 1.17 \\
\hline Jackson County & 4.24 & 1.08 \\
\hline NMRC (1-800 number respondents) & 3.71 & 1.27 \\
\hline NMRC (local officials) & 3.56 & 0.98 \\
\hline Portage (base-line respondents) & 4.12 & 1.37 \\
\hline Portage (follow-up respondents) & 4.17 & 1.29 \\
\hline Publishers Paper (entire sample) & 4.06 & 1.30 \\
\hline Metropolitan areas & 4.01 & 1.33 \\
\hline Rural Oregon & 4.38 & 1.08 \\
\hline \multicolumn{3}{|l|}{ Recycle to earn money } \\
\hline Barry County & 2.43 & 1.70 \\
\hline Huntington Woods & 1.96 & 1.32 \\
\hline Jackson County & 2.42 & 1.61 \\
\hline NMRC (1-800 number respondents) & 2.72 & 1.48 \\
\hline NMRC (local officials) & 3.56 & 1.42 \\
\hline Portage (base-line respondents) & 2.50 & 1.61 \\
\hline Portage (follow-up respondents) & 2.57 & 1.66 \\
\hline Publishers Paper (entire sample) & 2.24 & 1.53 \\
\hline Metropolitan areas & 2.24 & 1.52 \\
\hline Rural Oregon & 2.27 & 1.57 \\
\hline \multicolumn{3}{|c|}{ Recycle because it seems like the right thing to do } \\
\hline Barry County & 4.14 & 1.24 \\
\hline Huntington Woods & 3.53 & 1.32 \\
\hline Jackson County & 3.75 & 1.26 \\
\hline NMRC (1-800 number respondents) & 4.12 & 1.32 \\
\hline NMRC (local officials) & 3.47 & 1.23 \\
\hline Portage (base-line respondents) & 4.23 & 0.56 \\
\hline Portage (follow-up respondents) & 4.32 & 1.30 \\
\hline
\end{tabular}

aThe Monroe County survey instrument utilized a 4-point response scale thus not allowing direct comparisons. The Publishers Paper Company study did not include the last item. 
ferently than did the public. Local officials tended to overestimate the role monetary incentives play and slightly underestimate the strength of all the other motives.

Overall these data suggest that when promoting waste reduction and recycling one should include a discussion of non-monetary motives. Programs should concentrate on the effect recycling has on the environment, any benefits recycling may have for a charitable organization and the personal, intrinsic satisfaction gained from doing the right thing.

\section{CONCLUSION}

Interpreting data collected from surveys is always a challenging task. The task is made all the more challenging when the data are collected by others using a variety of data collection styles and sample sizes. Nonetheless, the findings remained consistent across the different surveys. The public, as represented by the respondents, holds a strong pro-recycling attitude, intends to increase their level of recycling behavior in the future and is greatly influenced by non-monetary motives. Recycling, once an aberrant and rarely practiced behavior, is becoming the social norm.

\section{ACKNOWLEDGEMENTS}

I would like to acknowledge support from the Michigan Department of Natural Resources (MDNR Project Number DPO 86-GA-8365) and in particular the MDNR contract coordinator, Robbe DiPietro, who was helpful throughout the project. I would also like to thank the many program staff members who helped design the questionnaires and collect the data, including Jackie Schmitz in Barry County, Lillian Dean in Huntington Woods, Misty Sheehan in Jackson County, Mario Dupuis and Jill Wiese in Monroe County, Doug Hyde at the Northern Michigan Recycling Coop and Mary Appelhof in Portage, Michigan.

\section{REFERENCES}

1 Van Valey, T.L., 1987. The Portage community survey: a summary report. Kercher Center for Social Research, Western Michigan University, Kalamazoo, MI, 13 pp.

2 Intercept Research Corporation - Brian Gard, Inc., 1984. Publishers Paper Company Recycling Attitudes and Behavior. Lake Oswego, OR, $124 \mathrm{pp}$.

3 Anonymous, 1982. The public's opinion of recycling. Resour. Recycl., 1:6-7.

4 City of Seattle, 1979. Recycling behavior and motivation in the general Seattle population and the SORT area residents. Seattle, Washington.

5 De Young, R., 1988-1989. Exploring the difference between recyclers and non-recyclers: the role of information. J. Environm. Syst., 18: 341-351. 
6 Geller, E.S., Winett, R.A. and Everett, P.B., 1982. Preserving the Environment: New Strategies for Behavioral Change. Pergamon Press, New York, 338 pp.

7 De Young, R., 1985-1986. Encouraging environmentally appropriate behavior: The role of intrinsic motivation. J. Environm. Syst., 15: 281-292. 